\title{
Fusion programme 'could aid terrorists'
}

Washington. A former US nuclear weapons designer has criticized a joint programme between the United States and Russia aimed at exploring new ways of producing fusion energy, claiming that it could produce information that terrorists could use to develop a miniature neutron bomb. Antinuclear organizations also say that the techniques being developed undermine nonproliferation efforts.

The programme between the Los Alamos National Laboratory (LANL) in New Mexico and its Russian counterpart, Arzamas 16, is part of the US Department of Energy's 'lab-to-lab' programme. This is intended to keep Russian weapons scientists gainfully employed, and to encourage them not to sell their services to countries bent on acquiring nuclear weapons.

The two laboratories have already carried out 18 joint experiments in which chemical explosives are used to create a powerful electrical pulse. This is converted into a magnetic field, which is then used to compress a pellet of deuterium and tritium, triggering thermonuclear fusion. Andrei Sakharov, the renowned Soviet weapons scientist and dissident, first proposed this approach in the $1950 \mathrm{~s}$.

But writing in the Wall Street Journal last month, Sam Cohen, a former weapons designer at LANL, claimed that while the experiments are a long way from creating a new source of fusion energy, they are creating a device with "all the hallmarks of a "pure fusion' neutron bomb" that could prove an ideal "briefcase bomb" for terrorists.

His thesis is that although the tiny amounts of fusion energy released in the experiments are insufficient for a fusion bomb, the devices that are being tested successfully burn deuterium and tritium to produce "deadly high-energy neutrons". This burning process is identical, he says, to that used in conventional neutron bombs. Cohen, who invented the neutron bomb, also claims that the US government abandoned similar research in the 1950s

\section{Commercial use of encryption backed}

Washington. The government should encourage the unrestricted commercial use of encryption technology within the United States, says a report from the National Research Council (NRC). The report, prepared by an NRC panel chaired by Kenneth Dam, professor of law at the University of Chicago, says that exports of the technology should also be subject to fewer controls. It criticizes the US government's attempts to persuade businesses to use cryptography to which the government has special access. after he had raised similar objections.

Cohen's warning has met with a mixed response. "Pretty darned far-fetched," says Paul White, programme manager in LANL's centre for international security affairs. "There is no practical way that any scientist could imagine of converting this into a bomb," he says, adding that even if Cohen's thesis is correct, any device would be too big to be useful as a weapon. Making a weapon from such a pulsed energy device would be comparable to making one from a tokamak fusion reactor, he adds.

But Cohen argues that documents from the programme show that it is expected soon to produce as much as 200 pounds of TNTequivalent fusion yield, and would release large quantities of lethal high-energy neutrons. Los Alamos National Laboratory confirms that an experiment of this yield is

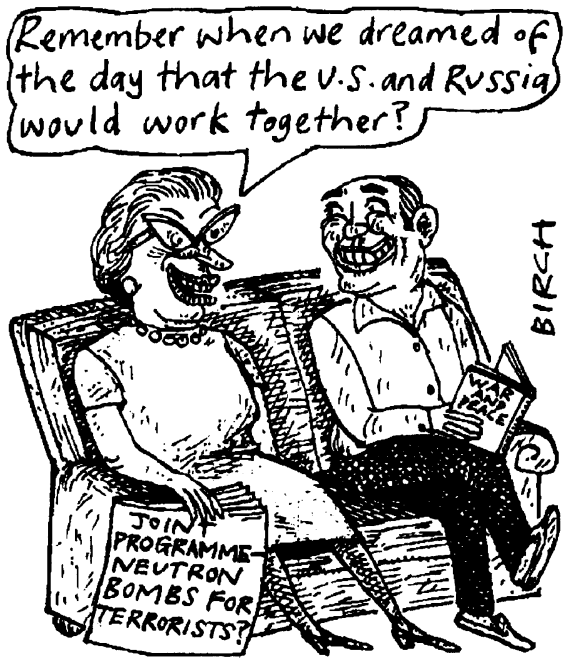

possible, but says that it will require the use of two of the one-ton devices (called generators), around 1,000 pounds of explosives and a one-ton capacitor bank. Hardly a deliverable weapon, White says, claiming that further miniaturization of the apparatus is unlikely, given that Russia has been optimizing such techniques for 40 years.

But Cohen points out that early nuclear devices were also bulky, whereas modern warheads can be the "size of a soccer ball". Moreover, he says that the experiments carried out seem to have overcome the technical hurdle that stymied years of earlier efforts by US weapons designers to develop a pure fusion weapon, namely creating an explosive nuclear device that does not require a fission trigger.

The latter claim is questioned by Stephen Dean, president of Fusion Power Associates, a group that promotes fusion energy. It is "almost impossible to imagine initiating a thermonuclear bomb without a nuclear trigger", says Dean. "The energy requirements are just too much; you can't get enough fuel ignited to produce a weapon."
White maintains that the experiments are designed merely to explore basic fusion and plasma science. "The very fact that we're collaborating with the Russians on this indicates that their defence people have totally discounted any military application of this," he says. He acknowledges that the experiments have produced neutrons, as would be expected if fusion had occurred. Further experiments will establish whether the magnetic fields can be used to confine a fusion plasma, he says.

But Theodore Taylor, a retired LANL weapons designer turned anti-nuclear activist, describes Cohen's alert as "appropriate". He adds: "We're both concerned there may be a strong weapons connection" to the LANL research. Taylor says that such fusion experiments will produce interesting physics, but that this is not enough to "balance the danger" of proliferation, particularly given the remote prospects that they could provide a new economic source of energy in the near future.

Christopher Paine, of the Natural Resources Defense Council, says he is less concerned about the immediate threat that the experiments might yield a pure fusion bomb than he is about the risk that other countries will use similar 'peaceful' fusion experiments as a cover for developing nuclear weapons. The information obtained from high explosive-driven implosion experiments can be used in the development of basic fission weapons, he says.

"Our fear is that by not explicitly banning high explosively driven fusion, you create a loophole" in the proposed Comprehensive Test Ban Treaty now being negotiated in Geneva (see Nature 381, 267; 1996), says Paine. "By legitimizing this type of research, you are opening up a new avenue of research in states that don't currently perform it."

LANL disputes this assertion, claiming that the experiments are not applicable to fission weapon implosion in that magnetic fields are used to compress directly the deuterium/tritium pellets, whereas fission weapons use a shock wave generated by high explosives to compress the fission core.

But both Cohen and Paine are ambivalent as to whether the experiments should be allowed to continue. Both admit that the cooperation between the United States and Russia on the programme brings political benefits. Russia is also bringing a technology to the table in which it has "a considerable lead", according to LANL.

Recognizing that the programme is unlikely to be stopped, Cohen says that one alternative would be to continue the project, but to give it "the highest degree of classification" in order to prevent the technology falling into the hands of proliferating nations. At present, the research programme is unclassified.

David Kramer 